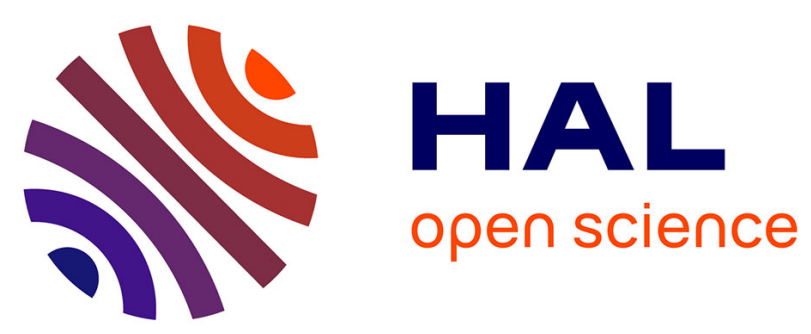

\title{
Permeation of probe molecules into alginate microbeads: Effect of salt and processing
}

\author{
P. van Leusden, G. J. M. den Hartog, A. Bast, M. Postema, E. van Der \\ Linden, L. M. C. Sagis
}

\section{- To cite this version:}

P. van Leusden, G. J. M. den Hartog, A. Bast, M. Postema, E. van Der Linden, et al.. Permeation of probe molecules into alginate microbeads: Effect of salt and processing. Food Hydrocolloids, 2017, 73, pp.255-261. 10.1016/j.foodhyd.2017.06.028 . hal-02498702

\section{HAL Id: hal-02498702 \\ https://hal.science/hal-02498702}

Submitted on 4 Mar 2020

HAL is a multi-disciplinary open access archive for the deposit and dissemination of scientific research documents, whether they are published or not. The documents may come from teaching and research institutions in France or abroad, or from public or private research centers.
L'archive ouverte pluridisciplinaire HAL, est destinée au dépôt et à la diffusion de documents scientifiques de niveau recherche, publiés ou non, émanant des établissements d'enseignement et de recherche français ou étrangers, des laboratoires publics ou privés. 


\section{Permeation of probe molecules into alginate microbeads: Effect of salt and processing}

Authors: P. van Leusden ${ }^{1}$, G.J.M. den $\operatorname{Hartog}^{2}$, A. Bast ${ }^{2}$, M. Postema ${ }^{3,4,5}$, E. van der Linden ${ }^{1}$, L.M.C. Sagis ${ }^{*}$

1 Physics and Physical Chemistry of Foods Group, Department of Agrotechnology and Food Sciences, Wageningen University, Bornse Weilanden 9, 6708 WG Wageningen, The Netherlands

2 Department of Pharmacology and Toxicology, Maastricht University, PO Box 616, 6200 MD Maastricht, The Netherlands

3 LE STUDIUM Loire Valley Institute for Advanced Studies, 1 rue Dupanloup, 45000 Orléans, France;

4 INSERM Research unit U930: Imaging and Brain, UFR Médecine, 10 boulevard Tonnellé, 37032 Tours, France;

5 School of Electrical and Information Engineering, Chamber of Mines Building, University of the Witwatersrand, 1 Jan Smuts Avenue, Braamfontein, Johannesburg 2050, South Africa.

* Corresponding author

Email address: leonard.sagis@wur.nl 


\section{Abstract}

The ability to exclude harmful factors from a hydrogel microbead is important for the degree of protection the beads offers to what is encapsulated within. The permeability of alginate microbeads, prepared by water-in-oil emulsification, was investigated by their ability to exclude FITC-labelled protein probes. The influence of alginate concentration, calcium concentration and method of addition, and salt content of the environment was investigated. The permeability was also compared to the permeability of beads made by the traditional method of dripping an alginate solution into a $\mathrm{CaCl}_{2}$ solution. Beads produced with low amounts of $\mathrm{CaCl}_{2}$ show a significant degree of swelling and are therefore very permeable $\left(\mathrm{C} / \mathrm{C}_{0}(\mathrm{BSA})=0.62\right.$, where $\mathrm{C}$ is the final concentration of BSA-FITC in the bead, and $\mathrm{C}_{0}$ the concentration of BSA-FITC in the continuous phase). With additional calcium, either by adding more calcium crystals after the emulsification step or by washing with a $\mathrm{CaCl}_{2}$ solution, beads swell less and are less permeable $\left(\mathrm{C} / \mathrm{C}_{0}(\mathrm{BSA})=0.13\right.$ and 0.12). Beads made by dripping are very permeable $\left(\mathrm{C} / \mathrm{C}_{0}(\mathrm{BSA}) \sim 0.60\right)$. Because in this process the droplets of alginate are not constrained by a water-oil boundary, the beads can swell during gelation. The salt concentration in the continuous phase influences the strength of the electrostatic repulsion between the probes and the alginate network and hence affects the permeation of the probes into the beads. In the absence of salt, even FITC (389Da) is mostly excluded from the interior of the beads $\left(\mathrm{C} / \mathrm{C}_{0}(\mathrm{FITC}) \sim 0.09\right)$.

Keywords: Alginate beads, permeability, microbeads, Debye length, salt concentration 


\section{Introduction}

Microencapsulation is the process of enclosing components within a microsystem to protect them from harmful factors in their environment. Hydrogel beads have been used to encapsulate living cells, and for delivery and controlled release of chemicals. Alginate is often used to create hydrogel beads because it is easily formed into beads and is generally qualified as safe for human application (de Vos, Lazarjani, Poncelet, \& Faas, 2014). Alginate beads have been used to encapsulate living cells such as chondrocytes (Bonaventure, et al., 1994), islet cells (Lim \& Sun, 1980) and bacteria (Covarrubias, de-Bashan, Moreno, \& Bashan, 2012; Lee \& Heo, 2000; Sultana, et al., 2000) and chemicals such as Blue dextran (Kim \& Lee, 1992), oil droplets (Chan, 2011; Li, Hu, Du, Xiao, \& McClements, 2011; Van Leusden, et al., 2016a), proteins such as BSA and insulin (Hari, Chandy, \& Sharma, 1996), and drugs such as verapamil (Pasparakis \& Bouropoulos, 2006) and doxorubicin (Liu, et al., 2010). For hydrogel beads to function as a protective barrier between a component and its environment, the ability of molecules from the surrounding phase to diffuse into the bead is a key design parameter.

An important factor determining the permeability of a bead is the pore size of the hydrogel matrix. The pore size affects the molecular weight cut off (MWCO) of species able to enter/leave the bead, and influence the drag forces on the components. The porosity of alginate microbeads is determined by the type of alginate (Martinsen, Skjåk-Bræk, \& Smidsrød, 1989; Martinsen, Storrø, \& Skjårk-Bræk, 1992; Mørch, Donati, Strand, \& SkjåkBræk, 2006), and its concentration (Martinsen, et al., 1992; Tanaka, Matsumura, \& Veliky, 1984), the type (Mørch, et al., 2006), concentration (Tanaka, et al., 1984) and method of addition of the gelling agent (Liu, et al., 2002; Skjåk-Bræk, Grasdalen, \& Smidsrød, 1989), and the properties of the environment of the bead, which includes factors such as the $\mathrm{pH}$, ionic strength, and temperature.

The most common method to make alginate beads is by dripping an alginate solution into a calcium chloride solution. This method typically produces beads larger than $300 \mu \mathrm{m}$ (Uludag, De Vos, \& Tresco, 2000), though beads around $100 \mu \mathrm{m}$ in size can be made with additional techniques like the JetCutter (Koch, Schwinger, Kressler, Heinzen, \& Rainov, 2003). This process is difficult to scale up because of the large number of nozzles required, and problems with sanitation and nozzle blockage. A comprehensive review on the preparation methods of 
alginate micro- and nanobeads has recently been published (Paques, van der Linden, van Rijn, \& Sagis, 2014). Paques et al. (2012) presented a new method to create smaller alginate microbeads. The alginate solution is emulsified in oil, after which a dispersion of calcium nanocrystals in oil is added. These crystals diffuse to the oil-alginate interface, where they dissolve and gel the bead externally. For this new method, the diffusive properties of the beads are still unknown. The difference in method of supplying the calcium ions between the W/O emulsification and the dripping method may have an effect on the gel morphology, and thus the porosity, of the bead.

In biotechnology and medicine, where alginate beads are typically used to encapsulate living cells, the porosity of alginate beads has been well investigated. The porosity is of importance because small nutrients and waste products should be able to freely diffuse in or out of the bead, while reactions with parts of the immune system such as immunoglobulins should be inhibited to protect the cells (Schuldt \& Hunkeler, 2000). In these studies the beads are tested is specific environments, such as $0.1 \mathrm{M}$ Tris-buffer or saline solution $(154 \mathrm{mM})$ with a $\mathrm{pH}$ of 7.4 (Hari, et al., 1996; Laca, García, Argüeso, \& Díaz, 1999; Martinsen, et al., 1989; Mørch, et al., 2006; Schaink, van Malssen, Morgado-Alves, Kalnin, \& van der Linden, 2007), in simulated gastric fluid, (Lee, et al., 2000; Pasparakis, et al., 2006) or in waste water (Covarrubias, et al., 2012). The environmental factors in other applications of alginate microbeads, such as foods or cosmetics, cover a much broader range and their effects on particle porosity is less well investigated. Ionic strength and $\mathrm{pH}$ will likely have an effect on the swelling behavior of the beads, the charge of the beads and probes, and the thickness of the Debye layer. Apart from the charge, these factors have barely been investigated in studies investigating the diffusive processes in alginate beads.

With respect to the influence of charge, several investigations (Gehrke, Fisher, Palasis, \& Lund, 1997; Huguet \& Dellacherie, 1996; Martinsen, et al., 1992; Matsuyama, Kitamura, \& Naramura, 1999) found that probes, including proteins and ions, with an opposite charge to the gel were attracted to the network, while probes with similar charge were repelled. The diffusion of neutral probes was related to their molecular weight.

Permeability of microbeads is an important factor for the degree of protection a microbead provides their cargo from its environment. Digestive enzymes such as pepsin or immunoproteins such as immunoglobulins should be excluded from the inside of the bead as 
much as possible. In this study, we investigated the permeability of alginate microbeads, prepared by the W/O emulsification method described by Paques et al. (2012), and the effect of alginate concentration, calcium concentration and method of addition, and salt concentration of the environment on the permeation of fluorescein isothiocyanate (FITC) and FITC-labelled protein probes through the alginate microbeads. The $\zeta$-potential, size and microstructure of the beads were investigated to further understand the properties influencing the permeability of the beads for these probes. Furthermore the difference in permeability of microbeads prepared with the emulsification method was compared to microbeads prepared by dripping an alginate solution into a $\mathrm{CaCl}_{2}$ bath . 


\section{Materials and methods}

\subsection{Materials}

$\mathrm{CaCl}_{2} \cdot \mathrm{H}_{2} \mathrm{O}$ (GR for analyses, Merck, Germany), ethanol absolute (Merck, Germany), Polyglycerol polyricinoleate (PGPR) 90 Kosher (Danisco, Denmark), Medium chain Triglycerides (MCT) (Miglyol 812 N) (Sasol, Germany), Sodium alginate extracted from brown algae (Algin, Texturas, Barcelona, Spain), $\beta$-lactoglobulin, ovalbumin and bovine serum albumin, FITC (Sigma Aldrich, Germany) were all used as received. Solutions were made in demineralized water.

\subsection{Preparation of Ca nanocrystals}

Calcium nanocrystals were prepared according to the method of Paques et al. (2012). In short, $5 \%(\mathrm{v} / \mathrm{v})$ of a 0.1 molal $\mathrm{CaCl}_{2} \cdot \mathrm{H}_{2} \mathrm{O}$ in ethanol solution was emulsified for 1 minute in MCT containing 6\% (w/w) PGPR with a Sonicator S-250A sonicator (Branson Ultrasonics, USA). This emulsion was heated overnight at $60^{\circ} \mathrm{C}$, while stirring continuously, to allow the ethanol to evaporate.

\subsection{Preparation of microbeads by W/O emulsification}

The method to prepare alginate microbeads was based on the method described by van Leusden et al. (2016a). Solutions of 1 and $2 \%$ (w/w) of alginate were made. To create the beads, a volume of $16 \%$ of the alginate solution was slowly added to MCT oil containing $4 \%$ (w/w) PGPR, while mixing with an Ultra-Turrax (Ultra-Turrax T 25, IKA Werke, Germany) at $4200(2 \%)$ or $3000(1 \%) \mathrm{rpm}$. After complete addition, the mixture was mixed for another 3 minutes. Per mL of emulsified alginate solution, 5 or $10 \mathrm{~mL}$ of crystal solution was added. The emulsion was allowed to set for at least 20 hours with continuous stirring on a magnetic stirrer.

The beads were removed from the oil phase by centrifuging the dispersion at $5000 \mathrm{~g}$ for 2 hours. The beads were washed to remove the residual oil, which was done by redispersing the pellet in water, homogenizing three times at 80 bar and then centrifuging at $2500 \mathrm{~g}$. Part of the beads were, in the first washing cycle, washed with $25 \mathrm{mM} \mathrm{CaCl}_{2}$ solution. The beads were washed 3 more times, either with demi-water or with an $\mathrm{NaCl}$ solution (either 25, or 100 $\mathrm{mM})$. 


\subsection{Preparation of large microbeads by dripping method}

Microbeads were prepared based on the method described by Li, et al. (2011). Approximately $2 \mathrm{~mL}$ of a $2 \%$ alginate solution was dripped into a $25 \mathrm{mM} \mathrm{CaCl}_{2}$ bath of $100 \mathrm{~mL}$ while stirring with a magnetic stirrer and allowed to set for 2 hours at room temperature. The needle had a diameter of $0.3 \mathrm{~mm}$ and the syringe was gently tapped to allow droplets to fall off the needle more quickly, creating beads of about $1 \mathrm{~mm}$. After gelation the beads were rinsed with either demi-water or 25 or $100 \mathrm{mM} \mathrm{NaCl}$ solution.

\subsection{Dynamic light scattering}

The size distribution of the microbeads was measured with a Mastersizer (Malvern Mastersizer 2000, Malvern Instruments, UK) using laser diffraction. The $\zeta$-potential of the beads and probes was measured with a Malvern Zetasizer (Malvern Instruments, UK). Obscuration was between 5 and $15 \%$ and the refractive index of calcium alginate gels was assumed to be 1.45 .

\subsection{CLSM}

The permeability of the beads was investigated with CLSM (Zeiss LSM5 Pascal confocal system, Carl Zeiss group, the Netherlands). The argon laser was used to excite the FITC molecules at $488 \mathrm{~nm}$ and the emission fluorescence was observed after passing a $505 \mathrm{~nm}$ BP filter. Fluorescent probes of different radii were made by binding FITC to $\beta$-lactoglobulin $(2.26 \mathrm{~nm})$ (Roefs \& de Kruif, 1999), ovalbumin $(3.20 \mathrm{~nm})$ and BSA (3.93 nm) (Pluen, Netti, Jain, \& Berk, 1999). FITC was dissolved in DMSO in $2 \mathrm{mg} / \mathrm{mL}$ and protein solutions of $1 \%$ (w/w) were prepared in $100 \mathrm{mM}$ carbonate buffer ( $\mathrm{pH} 9.0)$. A volume of 50uL FITC solution was added per $\mathrm{mL}$ of $1 \%$ protein solution, and allowed to react for 5 hours. After incubation the FITC-protein solutions were transferred to dialysis membranes and dialysed against carbonate buffer (4 times), and demi-water or $100 \mathrm{mM} \mathrm{NaCl}$ solution (3 times). The unbound FITC was also used as a probe. The probe solutions were added to the bead solution in a ratio of $1: 4$, giving a probe concentration of $0.2 \%(\mathrm{w} / \mathrm{w})$. The $\mathrm{pH}$ was 6.9 and the solutions had ionic strengths of 0,25 or $100 \mathrm{mM}$. To investigate the permeation of the probes into the bead the intensity of the fluorescence of the entire surface of at least 10 beads was measured and compared with the intensity of the fluorescence outside the beads, giving a ratio $\mathrm{I} / \mathrm{I}_{0}$, which is assumed to be equal to the ratio of the concentration of the probes in the bead $\mathrm{C}$, and the concentration of the probe in the continuous phase $\mathrm{C}_{0}$. The intensities were measured with the 
software ImageJ. Equilibrium was achieved within 2 minutes for the W/O beads and after about 15 minutes for the beads produced by dripping. Measurements were taken after 4 hours when equilibrium was established.

\subsection{SEM}

The microstructure of the beads was investigated with scanning electron microscopy (SEM; Magellan 400, FEI, Eindhoven, the Netherlands). The samples were adhered to poly-L-lysine coated coverslips and fixed with a 3\% glutaraldehyde solution. Next the samples were dehydrated using a series of 30, 50, 70 and $100 \%(\mathrm{v} / \mathrm{v})$ acetone solutions after which the samples were critical point dried. The large beads were not adhered to the cover slips but dried as loose beads. The dried, large beads were cut open with a knife and mounted on a stub using carbon adhesive tape. The samples were coated with a layer of $10 \mathrm{~nm}$ tungsten. 


\section{Results and discussion}

\section{$3.1 \zeta$-potential}

The $\zeta$-potential is an important factor in whether permeation of a probe molecule into a porous bead is possible. The $\zeta$-potential of the protein probes in $100 \mathrm{mM} \mathrm{NaCl}$ solution was measured to be: $\beta$-lactoglobulin $-11.1( \pm 0.1) \mathrm{mV}$, Ovalbumin $-10.6( \pm 0.4) \mathrm{mV}$ and BSA -10.7 $( \pm 0.2) \mathrm{mV}$. FITC was also used as a probe, but due to its small size its $\zeta$-potential cannot be measured with a Zetasizer. The mixture of alginate beads and FITC solution in $100 \mathrm{mM} \mathrm{NaCl}$ had a pH of 6.9. The pKa of FITC is 6.35 (Lavis, Rutkoski, \& Raines, 2007), therefore under these circumstances the molecules are mostly negatively charged. The $\zeta$-potential of the various alginate microbeads can be found in Table 1.

We observe that under the conditions used in this study, all probes and beads are negatively charged, and the resulting repulsion between probe and bead matrix can affect the permeation of the probes into the bead.

Table 1: $\zeta$-potential of alginate beads prepared by W/O emulsification with varying alginate concentrations, various methods of adding additional calcium ( 0 : without extra calcium, 25 : washed with $25 \mathrm{mM}$ calcium solution, D: with double the amount of calcium crystals), and in solutions with varying $\mathrm{NaCl}$ concentration.

\begin{tabular}{ccc|l}
$\begin{array}{l}\text { [Alg] } \\
\%(\mathrm{w} / \mathrm{w})\end{array}$ & Calcium & $\begin{array}{l}{[\mathrm{NaCl}]} \\
(\mathrm{mM})\end{array}$ & $\begin{array}{l}\zeta \text {-potential } \\
(\mathrm{mV})\end{array}$ \\
\hline 2 & 0 & 100 & $-26.8( \pm 0.7)$ \\
& 25 & 100 & $-24.3( \pm 0.6)$ \\
& $\mathrm{D}$ & 100 & $-25.5( \pm 1.1)$ \\
\hline 1 & 0 & 100 & $-24.8( \pm 0.9)$ \\
& 25 & 100 & $-25.3( \pm 1.3)$ \\
& $\mathrm{D}$ & 100 & $-25.5( \pm 0.3)$ \\
\hline 2 & 25 & 0 & $-40.6( \pm 1.0)$ \\
& 25 & 25 & $-38.2( \pm 0.5)$ \\
& $(25$ & 100 & $-24.3( \pm 0.6))$
\end{tabular}




\subsection{Swelling}

The swelling of the beads is important because when a bead swells, the MWCO of molecules which can permeate into the bead also increases (King, Daugulis, Faulkner, \& Goosen, 1987). The $\zeta$-potential showed that the beads were negatively charged at $\mathrm{pH} 6.9$, and will repel other negatively charged colloids. This however also means that there is repulsion between the polysaccharides within the bead, which can lead to swelling. The degree of swelling is dependent on the charge of the polysaccharides, the ionic strength of the environment, and the gel characteristics of the beads themselves, such as alginate concentration and type and number of junction zones. The results of the bead size measurements can be found in Table 2 .

Table 2: Average diameter $\left(\mathrm{D}_{43}\right)$ of alginate beads prepared by W/O emulsification with varying alginate concentrations, various methods of adding additional calcium (0: without extra calcium, 25: washed with $25 \mathrm{mM}$ calcium solution, D: with double the amount of calcium crystals), at various $\mathrm{NaCl}$ concentrations.

\begin{tabular}{ccc|c}
$\begin{array}{l}{[\mathrm{Alg}]} \\
\%(\mathrm{w} / \mathrm{w})\end{array}$ & Calcium & $\begin{array}{c}{[\mathrm{NaCl}]} \\
(\mathrm{mM})\end{array}$ & Diameter $(\mu \mathrm{m})$ \\
\hline 2 & 0 & 100 & $14.67( \pm 0.02)$ \\
& 25 & 100 & $13.49( \pm 0.12)$ \\
& $\mathrm{D}$ & 100 & $11.28( \pm 0.01)$ \\
\hline 1 & 0 & 100 & $11.25( \pm 0.01)$ \\
& 25 & 100 & $11.11( \pm 0.01)$ \\
& $\mathrm{D}$ & 100 & $11.40( \pm 0.05)$ \\
\hline 2 & 25 & 0 & $8.71( \pm 0.00)$ \\
& 25 & 25 & $11.39( \pm 0.02)$ \\
& $(25$ & 100 & $13.49( \pm 0.12))$ \\
\hline \multicolumn{3}{c|}{$2 \%$ alginate emulsion } & $10.57( \pm 0.03)$ \\
$1 \%$ alginate emulsion & $10.13( \pm 0.06)$
\end{tabular}

For the $1 \%$ beads, all the beads swelled when removed from the oil. The swelling of the $1 \%$ alginate beads was not affected by the addition of extra $\mathrm{CaCl}_{2}$, and was $39 \pm 6 \%$ (v/v), which means that the extra calcium, either in the form of extra crystals or in solution, did not create a stronger structure, more resistant to swelling. The $2 \%$ beads washed with $\mathrm{CaCl}_{2}$ solution and 
$2 \%$ beads without extra calcium swelled more than the $1 \%$ beads, respectively $108 \%$ and $167 \%(\mathrm{v} / \mathrm{v})$. The $1 \%$ and $2 \%$ beads are prepared with equal amounts of calcium, but the higher concentration of alginate in the $2 \%$ beads is assumed to result in a longer segment length between junction zones. This results in a more flexible structure which can swell more. The $2 \%$ beads that were gelled with extra calcium nanocrystals were smaller than the beads washed with $\mathrm{CaCl}_{2}$ solution, and showed a swelling of about $22 \%(\mathrm{v} / \mathrm{v})$. When the extra calcium is added while the bead is removed from the oil phase, which happens when the bead is washed with a calcium solution, the bead can swell before the additional calcium can rigidify the structure, since it takes time for the calcium ions to diffuse into the bead. When the extra calcium is added while the bead is still within the oil phase, as is the case when extra calcium nanocrystals are added to the oil, the additional calcium can rigidify the bead matrix before it is transferred to the water phase, thereby reducing the degree of swelling. The beads that swelled least were expected to be the least porous.

\subsection{Permeability}

Figure 1 shows a selection of CLSM images showing different degrees of permeation of probes (FITC, $\beta$-lac and BSA) into $2 \%$ alginate beads treated with different amounts of calcium (without extra calcium, washed with a calcium solution, and gelled with extra calcium crystals) in $100 \mathrm{mM} \mathrm{NaCl}$ solution after 4 hours. The intensity of at least 10 beads was compared to the intensity of the signal outside the beads, from which we calculated $\mathrm{C} / \mathrm{C}_{0}$. The results for $\mathrm{C} / \mathrm{C}_{0}$ are presented in Figures 2 through 4.

\subsubsection{2\% Alginate beads prepared by W/O emulsification}

Figure 2 shows the permeation of the FITC labelled probes through the alginate beads, made with $2 \%$ alginate, after 4 hours, in $100 \mathrm{mM} \mathrm{NaCl}$. There is an overall decrease in permeation when the size of the probe increases. Between the 3 calcium concentrations it is obvious that the beads that have not been treated with extra calcium show a much higher degree of permeation of the probes. For ovalbumin there is 3 times more probe present in the beads prepared without extra calcium as opposed to the ones which were prepared with additional calcium, either through an increase of nanocrystals in the exterior oil phase, or by washing with $\mathrm{CaCl}_{2}$ solution. When considering the swelling results, it can be seen that the size of the beads increased from 10.57 um to $14.68 \mathrm{um}$, which allowed for the permeation of more and larger probe molecules. There is little difference in permeation between the samples treated 
with extra calcium, either by addition of extra nanocrystals or by washing with $\mathrm{CaCl}_{2}$ solution. There is however a large difference in swelling between these beads, which have a final average diameter of 11.28 and $13.49 \mu \mathrm{m}$ respectively. The degree of swelling by itself is therefore not a sufficient characteristic to base the expected permeation on. Though swelling is likely to have an influence, because it increases the average pore size, additional changes in the microstructure induced by the different modes of adding the additional calcium appear to play a role in the observed permeability.

\subsubsection{1\% Alginate beads prepared by W/O emulsification}

The experiment was repeated with microbeads with a $1 \%$ alginate concentration, the results of which can be found in Figure 3. The beads washed with demi-water allow for most permeation, followed by the beads washed with $25 \mathrm{mM}$ calcium solution and the beads prepared with a higher concentration of crystals in the oil phase. For ovalbumin the probe concentration in the beads without extra calcium is 1.2 times higher than for the beads with extra calcium. The degree of permeation into the beads treated with additional calcium is higher than their counterparts prepared with $2 \%$ alginate, specifically, for ovalbumin it is twice as high. The lower amount of alginate present created a more porous structure. The difference between the beads prepared with and without extra calcium is however not as high and there is less probe present in the $1 \%$ beads without extra calcium than in the $2 \%$ beads without extra calcium. The swelling of the $1 \%$ beads is also less than that of the $2 \%$ beads, $37 \%$ vs $167 \%$ (v/v). The $1 \%$ and $2 \%$ beads were prepared with the same amount of $\mathrm{CaCl}_{2}$, which means that the calcium to alginate ratio in the $1 \%$ beads is twice as high as in the $2 \%$ beads. This may have resulted in more crosslinks per alginate chain, thereby creating a less flexible structure. Beads made with $1 \%$ alginate and half the original amount of calcium crystals were weak and fractured during extraction from the oil phase.

\subsubsection{Effects of salt concentration}

Figure 4 shows the effect of the salt concentration of the continuous phase on the permeation of the protein probes in the $2 \%$ beads washed with $25 \mathrm{mM}$ calcium solution.

In the absence of sodium chloride not even FITC can diffuse into the alginate bead. The physical pores of the alginate bead are large enough for this molecule to enter the bead, because at a salt concentration of $100 \mathrm{mM} \mathrm{NaCl}$, ovalbumin, which has a molecular weight about 100 times higher than FITC (389 Da vs. $44 \mathrm{kDa}$ ), can diffuse into the bead. The volume 
of the beads at 0 and $100 \mathrm{mM} \mathrm{NaCl}$ differs only by a factor of 3.7. The inability of FITC to penetrate the bead therefore cannot just be attributed to the shrinkage of the beads. The $\zeta-$ potential of both the beads and the probes is negative (Table 1) which results in a repulsion between the probe and the bead, and this significantly reduces the permeation of the probes into the beads. Electrostatic interactions are dependent on both the charge of the particles, and the width of the electrical double layer (the Debye length). The charge and concentration of the ions is very important for the thickness of this layer.

At $100 \mathrm{mM}$, the Debye length is about $1 \mathrm{~nm}$. When decreasing the $\mathrm{NaCl}$ concentration from $100 \mathrm{mM}$ to $25 \mathrm{mM}$, the Debye length doubles. When comparing the results of beads in 25 $\mathrm{mM}$ and $100 \mathrm{mM} \mathrm{NaCl}$ we find that for FITC and $\beta$-lac the amount of probe able to diffuse into the beads is both 1.9 times higher at $100 \mathrm{mM}$ than at $25 \mathrm{mM} \mathrm{NaCl}$. Our observation therefore confirms the effects of the Debye length on permeation. The influence of charge and ionic strength can only be disregarded when either the ionic strength is very high or the probe or bead is entirely without charge.

When investigating the pore size of a gelled material, this size is not simply given by the maximum size of the probe which can still permeate into the gel. The range of the repulsive interactions between the probe and the alginate bead, as represented schematically in Figure 5, should also be taken into account. This also explains why the concentration of probe in the bead $\left(\mathrm{C} / \mathrm{C}_{0}\right)$ in this study is never equal to the concentration outside the bead. A part may be ascribed to excluded volume of the alginate network itself, but part is caused by the repulsion resulting from the negative charges of the alginate molecules in the network. In this study the influence of $\mathrm{pH}$ was not investigated. Probes will be more charged far above their $\mathrm{pKa}$ or far from their iso electric point. Hence we expect that the permeability of the microbeads for certain probes will also be affected by the $\mathrm{pH}$ of the continuous phase.

\subsubsection{Beads made by dripping}

The permeability of the alginate beads produced with the method of Paques et al. (2012), followed by washing with calcium chloride solution has also been compared with the porosity of alginate beads produced with the common dripping method. The results of beads made with the dripping method can be found in Figure 6. 
Here too, when no salt is present in the continuous phase, only a small amount of FITC can permeate through the bead. Beads dispersed in $100 \mathrm{mM} \mathrm{NaCl}$ have a 1.74 times higher diffusion of ovalbumin into the bead than beads dispersed into $25 \mathrm{mM} \mathrm{NaCl}$. This difference is similar to the difference in permeability of the emulsified beads dispersed in 25 and 100 $\mathrm{mM} \mathrm{NaCl}$ (1.86). The overall permeation of the probes in beads prepared with the dripping method is higher than for beads prepared with the W/O emulsification method. For ovalbumin in $100 \mathrm{NaCl}$, the amount of probe present in the beads made with the dripping method is almost 3 times as high as in the beads made with the method of Paques et al. (2012). With both methods it is assumed that a surplus of calcium was present and thus the optimal ratio of alginate and calcium was achieved. The different method to create and gel the beads has thus influenced the pore size of the network. There are two possible reasons why this difference exists, either because of the different introduction of calcium into the system, or because of the different environments in which the beads are formed.

Skjak-Braek, et al. (1989) investigated inhomogeneity in macroscopic calcium-gelled polysaccharide cylinders with a diameter of 14 or $19 \mathrm{~mm}$. They found that the calcium concentration in the external phase was very important during external gelation of alginate. Because of a steep concentration gradient between gelled alginate at the interface of the cylinders, and unbound alginate away from the interface, unbound alginate diffuses to the interface. At $5 \mathrm{mM}$ calcium concentration in the external bath, the centre of an alginate tube contained $0.2 \%$ alginate, while at the surface the alginate concentration was $6 \%$. At higher calcium concentrations in the bath, and in the presence of other ions this difference in alginate concentration between inner and outer part of the cylinders decreased. With the new method of alginate bead gelation that Paques et al. presented, the solid calcium crystals diffuse to the interface where they dissolve and gel the alginate. This method most likely gives a relatively lower concentration of calcium at the interface of the bead when compared to dripping alginate droplets in a calcium chloride bath. This lower concentration allows for more diffusion of alginate to the interface, giving a denser surface of the bead when compared to the common dripping method. Previously we found that (van Leusden, et al., 2016b) cold-set protein beads of $10 \%$ whey protein isolate, also externally gelled with calcium nanocrystals, could delay diffusion of FITC-Dextran $(40 \mathrm{kDa})$ to the centre of the bead by several minutes, while a heat-set protein bead of $25 \%$ WPI could not. For the alginate beads in this study we could not observe a delayed diffusion of probe into the beads, since here the degree of 
permeation was measured after 4 hours, and equilibrium was already reached within several minutes.

The difference in permeability of the beads made by dripping versus the method of Paques, et al. could be caused by the different environments in which the beads are created. When the beads are dripped into the calcium bath the beads can swell during gelation. The beads made by the method of Paques are constrained by their oil-water interface and cannot swell during gelation. Only after the first gelation step, when introduced into the $25 \mathrm{mM}$ calcium solution, is the bead able to swell. King (1987) previously concluded that swelling might be accommodated by an increase in permeability. Most likely both these factors play a role when explaining the difference between the different calcium concentrations in the 1 and $2 \%$ beads, and between the beads prepared by dripping and beads made with the W/O emulsification method.

\subsection{Microstructure}

Previously we found that, though there is a difference in swelling between the $2 \%$ beads washed with $\mathrm{CaCl}_{2}$ solution, and beads gelled with double the amount of calcium crystals, there is little difference in permeability. We also found that the microbeads made with the W/O emulsification method had a far lower permeability than the beads made by dripping an alginate solution in a $\mathrm{CaCl}_{2}$ bath, despite both having been exposed to a surplus of calcium ions. To further investigate these two observations we investigated the microstructure of the beads with SEM, see Figure 7. Important to note is that, although the structure of the beads have been fixed during the sample preparation procedure, slight swelling or shrinking might still occur during the dehydration step, especially for weaker structures.

When comparing the beads washed with $\mathrm{CaCl}_{2}$ solution and the beads made by dripping in a $\mathrm{CaCl}_{2}$ solution, a large difference in structure can be seen. Despite having both been exposed to a surplus of calcium ions, the beads made by dripping have a thick stranded and much more open structure. It is likely that the beads made by the W/O method have a much denser structure because they have been constrained by the oil-water interface of the emulsion droplet during gelation, while the beads made by dripping in a $\mathrm{CaCl}_{2}$ solution had time to swell before the structure was fully gelled, thereby creating a much more open structure. Although the exact rate of release of calcium from the calcium crystals at the interface is unknown, it is likely that the slower release of calcium into the system, as opposed to the 
quick diffusion of calcium ions when creating beads made by dripping, allowed for the formation of a more fine stranded structure.

When comparing the beads washed with $\mathrm{CaCl}_{2}$ solution and the beads gelled with extra calcium crystals a difference in homogeneity can be seen. The higher amount of calcium crystals caused a higher amount of calcium to be released at the interface, thereby creating a more inhomogeneous structure with larger pores. Where the beads washed with $\mathrm{CaCl}_{2}$ solution had a higher permeation because the beads swelled before being fully gelled, the permeation of the beads gelled with extra calcium crystals had a higher permeation because of the bigger pores in the microstructure.

Little difference is seen between the beads washed with $\mathrm{CaCl}_{2}$ solution and beads without extra calcium. We expected to see much larger pores in the beads without extra calcium. These beads are however quite weak because of their low amount of calcium ions and may have shrunk during the dehydration step. 


\section{Conclusions}

In this study we investigated the difference between the permeation of probe molecules into alginate beads made under various conditions to compare their ability to prevent harmful factors from diffusion into the interior of the bead.

At low calcium concentrations, swollen and porous beads are created. Additional calcium ions can be added by washing the beads with a $\mathrm{CaCl}_{2}$ solution. This creates a stronger structure with small pores, which swells little and allows for less permeation. Additional calcium ions can also be added by adding extra calcium crystals in the exterior oil phase. These beads were most resistant to swelling, but the higher concentration of calcium ions created a structure with larger pores, which thus gave a similar permeability to the beads washed with $\mathrm{CaCl}_{2}$ solution.

The W/O emulsification method creates smaller and less permeable alginate networks than the dripping method. The constraints of the emulsion droplet and the slower release of calcium ions into the system created a more fine stranded and denser structure than for the beads made by dripping.

The $\zeta$-potential and Debye length are very important for the diffusion of charged probes in a charged network. Even very small molecules can be excluded from an alginate network when no salt is present. 


\section{Acknowledgements}

The research presented in this paper was financially supported by the Graduate School VLAG, of Wageningen University. M. Postema has received funding from the European Union's Horizon 2020 research and innovation programme under the Marie SkłodowskaCurie grant agreement No 665790. 


\section{References}

Bonaventure, J., Kadhom, N., Cohen-Solal, L., Ng, K. H., Bourguignon, J., Lasselin, C., \& Freisinger, P. (1994). Reexpression of Cartilage-Specific Genes by Dedifferentiated Human Articular Chondrocytes Cultured in Alginate Beads. Experimental Cell Research, 212(1), 97-104.

Chan, E.-S. (2011). Preparation of Ca-alginate beads containing high oil content: Influence of process variables on encapsulation efficiency and bead properties. Carbohydrate Polymers, 84(4), 1267-1275.

Covarrubias, S. A., de-Bashan, L. E., Moreno, M., \& Bashan, Y. (2012). Alginate beads provide a beneficial physical barrier against native microorganisms in wastewater treated with immobilized bacteria and microalgae. Applied Microbiology and Biotechnology, 93(6), 2669-2680.

de Vos, P., Lazarjani, H. A., Poncelet, D., \& Faas, M. M. (2014). Polymers in cell encapsulation from an enveloped cell perspective. Advanced Drug Delivery Reviews, 67-68, 15-34.

Gehrke, S. H., Fisher, J. P., Palasis, M., \& Lund, M. E. (1997). Factors determining hydrogel permeability. Annals of the New York Academy of Sciences, 831(1), 179-184.

Hari, P., Chandy, T., \& Sharma, C. P. (1996). Chitosan/calcium-alginate beads for oral delivery of insulin. Journal of Applied Polymer Science, 59(11), 1795-1801.

Huguet, M. L., \& Dellacherie, E. (1996). Calcium alginate beads coated with chitosan: Effect of the structure of encapsulated materials on their release. Process Biochemistry, $31(8), 745-751$.

Kim, C.-K., \& Lee, E.-J. (1992). The controlled release of blue dextran from alginate beads. International Journal of Pharmaceutics, 79(1), 11-19.

King, G., Daugulis, A., Faulkner, P., \& Goosen, M. (1987). Alginate-Polylysine Microcapsules of Controlled Membrane Molecular Weight Cutoff for Mammalian Cell Culture Engineering. Biotechnology Progress, 3(4), 231-240.

Koch, S., Schwinger, C., Kressler, J., Heinzen, C., \& Rainov, N. (2003). Alginate encapsulation of genetically engineered mammalian cells: comparison of production devices, methods and microcapsule characteristics. Journal of Microencapsulation, 20(3), 303-316.

Laca, A., García, A. L., Argüeso, F., \& Díaz, M. (1999). Protein diffusion in alginate beads monitored by confocal microscopy. The application of wavelets for data reconstruction and analysis. Journal of Industrial Microbiology and Biotechnology, 23(3), 155-165.

Lavis, L. D., Rutkoski, T. J., \& Raines, R. T. (2007). Tuning the pK(a) of Fluorescein to Optimize Binding Assays. Analytical chemistry, 79(17), 6775-6782.

Lee, K.-Y., \& Heo, T.-R. (2000). Survival of Bifidobacterium longumImmobilized in calcium alginate beads in simulated gastric juices and bile salt solution. Applied and Environmental Microbiology, 66(2), 869-873.

Li, Y., Hu, M., Du, Y., Xiao, H., \& McClements, D. J. (2011). Control of lipase digestibility of emulsified lipids by encapsulation within calcium alginate beads. Food Hydrocolloids, 25(1), 122-130.

Lim, F., \& Sun, A. M. (1980). Microencapsulated islets as bioartificial endocrine pancreas. Science, 210(4472), 908-910.

Liu, J., Zhang, Y., Wang, C., Xu, R., Chen, Z., \& Gu, N. (2010). Magnetically sensitive alginate-templated polyelectrolyte multilayer microcapsules for controlled release of doxorubicin. The Journal of Physical Chemistry C, 114(17), 7673-7679. 
Liu, X. C., Yu, W. Y., Zhang, Y., Xue, W. M., Yu, W. T., Xiong, Y., Ma, X. Y., Chen, Y., \& Yuan, Q. (2002). Characterization of structure and diffusion behaviour of Ca-alginate beads prepared with external or internal calcium sources. Journal of Microencapsulation, 19(6), 775-782.

Martinsen, A., Skjåk-Bræk, G., \& Smidsrød, O. (1989). Alginate as immobilization material: I. Correlation between chemical and physical properties of alginate gel beads. Biotechnology and Bioengineering, 33(1), 79-89.

Martinsen, A., Storrø, I., \& Skjårk-Bræk, G. (1992). Alginate as immobilization material: III. Diffusional properties. Biotechnology and Bioengineering, 39(2), 186-194.

Matsuyama, H., Kitamura, Y., \& Naramura, Y. (1999). Diffusive permeability of ionic solutes in charged chitosan membrane. Journal of Applied Polymer Science, 72(3), 397-404.

Mørch, Ý. A., Donati, I., Strand, B. L., \& Skjåk-Bræk, G. (2006). Effect of $\mathrm{Ca}^{2+}, \mathrm{Ba}^{2+}$, and $\mathrm{Sr}^{2+}$ on alginate microbeads. Biomacromolecules, 7(5), 1471-1480.

Paques, J. P., van der Linden, E., Sagis, L. M. C., \& van Rijn, C. J. M. (2012). Food-Grade Submicrometer Particles from Salts Prepared Using Ethanol-in-Oil Mixtures. Journal of Agricultural and Food Chemistry, 60(34), 8501-8509.

Paques, J. P., van der Linden, E., van Rijn, C. J. M., \& Sagis, L. M. C. (2012). Alginate submicron beads prepared through w/o emulsification and gelation with $\mathrm{CaCl} 2$ nanoparticles. Food Hydrocolloids, 31(2), 428-434.

Paques, J. P., van der Linden, E., van Rijn, C. J. M., \& Sagis, L. M. C. (2014). Preparation methods of alginate nanoparticles. Advances in Colloid and Interface Science, 209(0), 163-171.

Pasparakis, G., \& Bouropoulos, N. (2006). Swelling studies and in vitro release of verapamil from calcium alginate and calcium alginate-chitosan beads. International Journal of Pharmaceutics, 323(1-2), 34-42.

Pluen, A., Netti, P. A., Jain, R. K., \& Berk, D. A. (1999). Diffusion of Macromolecules in Agarose Gels: Comparison of Linear and Globular Configurations. Biophysical journal, 77(1), 542-552.

Roefs, P., \& de Kruif, K. G. (1999). Association behavior of native B-lactoglobulin. Biopolymers, 49, 11-20.

Schaink, H. M., van Malssen, K. F., Morgado-Alves, S., Kalnin, D., \& van der Linden, E. (2007). Crystal network for edible oil organogels: Possibilities and limitations of the fatty acid and fatty alcohol systems. Food Research International, 40(9), 1185-1193.

Schuldt, U., \& Hunkeler, D. (2000). Characterization methods for microcapsules. Minerva Biotecnologica, 12(4), 249.

Skjåk-Bræk, G., Grasdalen, H., \& Smidsrød, O. (1989). Inhomogeneous polysaccharide ionic gels. Carbohydrate Polymers, 10(1), 31-54.

Sultana, K., Godward, G., Reynolds, N., Arumugaswamy, R., Peiris, P., \& Kailasapathy, K. (2000). Encapsulation of probiotic bacteria with alginate-starch and evaluation of survival in simulated gastrointestinal conditions and in yoghurt. International Journal of Food Microbiology, 62(1-2), 47-55.

Tanaka, H., Matsumura, M., \& Veliky, I. A. (1984). Diffusion characteristics of substrates in Ca-alginate gel beads. Biotechnology and Bioengineering, 26(1), 53-58.

Uludag, H., De Vos, P., \& Tresco, P. A. (2000). Technology of mammalian cell encapsulation. Advanced Drug Delivery Reviews, 42(1), 29-64.

Van Leusden, P., Den Hartog, G., Bast, A., Postema, M., Van der Linden, E., \& Sagis, L. (2016a). Strength of microbeads for the encapsulation of heat sensitive, hydrophobic components. Food Hydrocolloids, 56, 318-324. 
van Leusden, P., den Hartog, G., Bast, A., Postema, M., van der Linden, E., \& Sagis, L. (2016b). Structure engineering of filled protein microbeads to tailor release of oil droplets in gastric digestion. Food \& function, 7(8), 3539-3547. 
Figures

Figure 1:
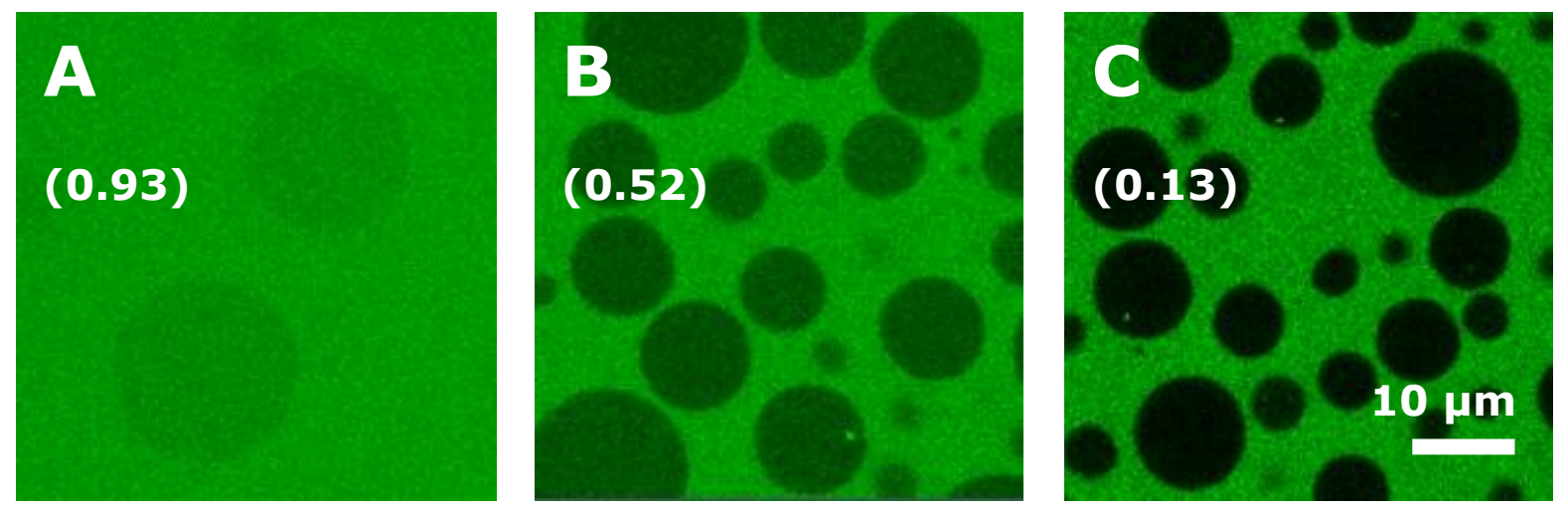
Figure 2:

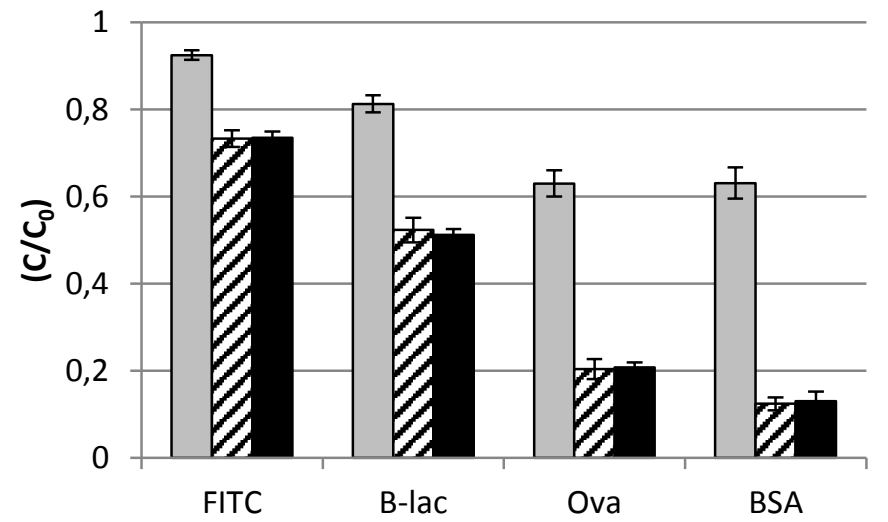


Figure 3:

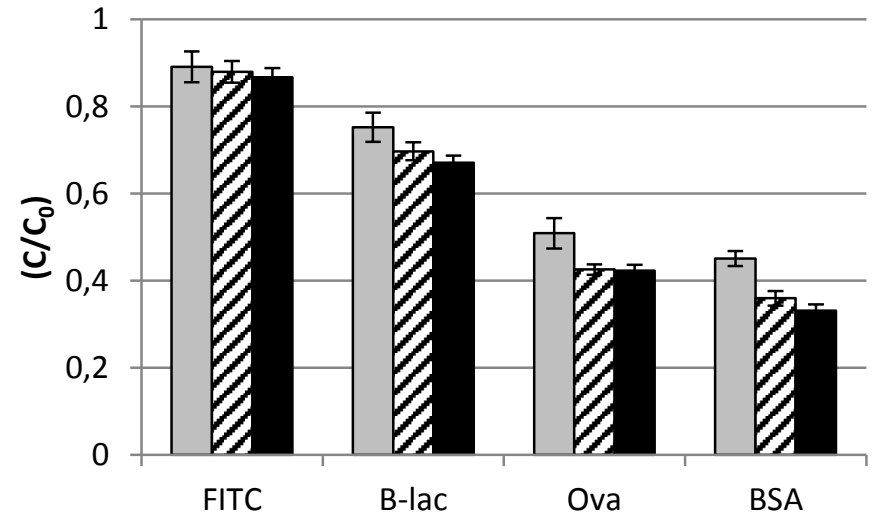


Figure 4:

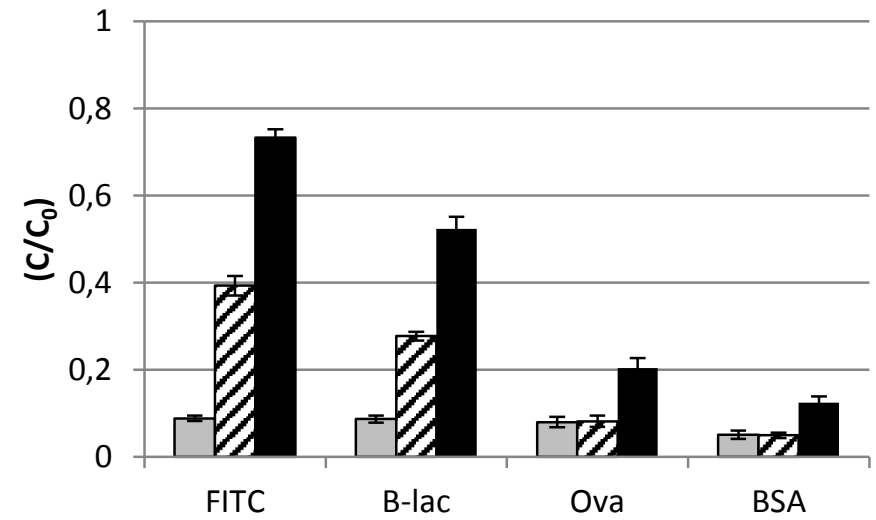


Figure 5:

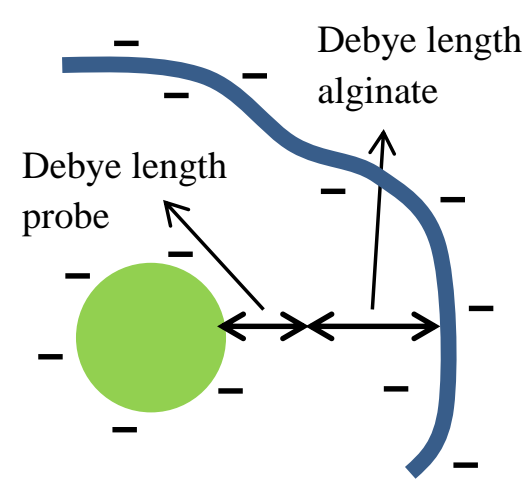

26 
Figure 6:

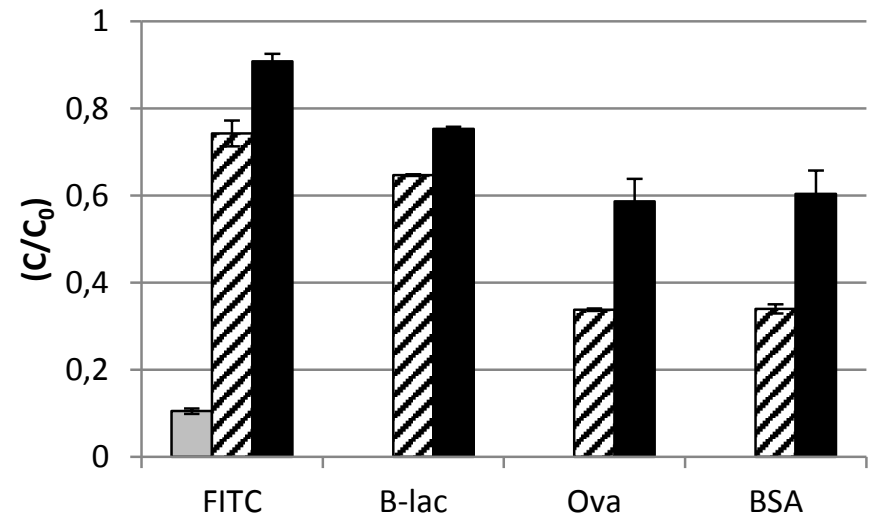


Figure 7:
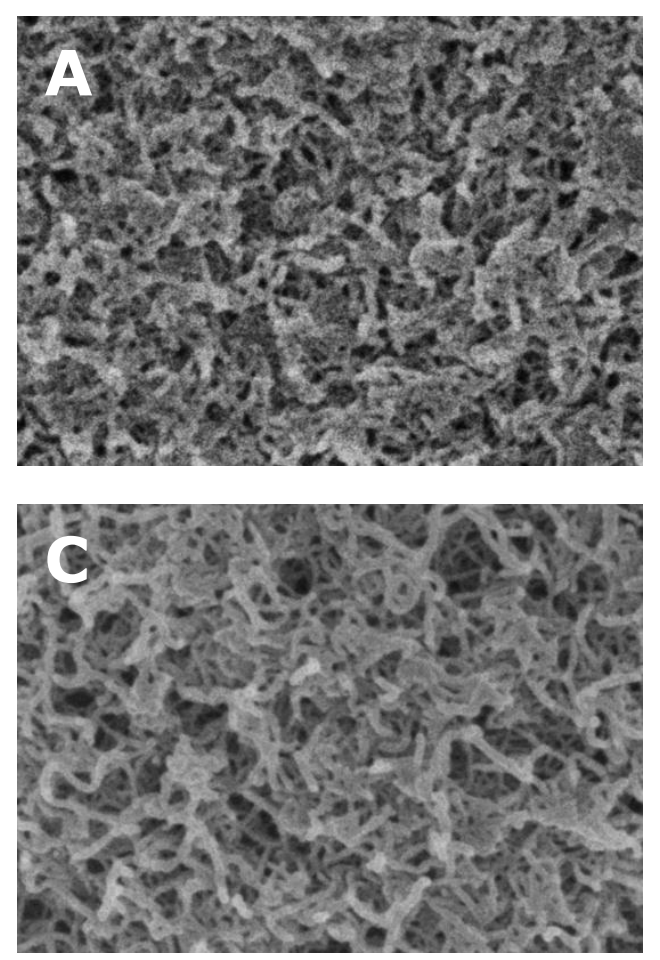
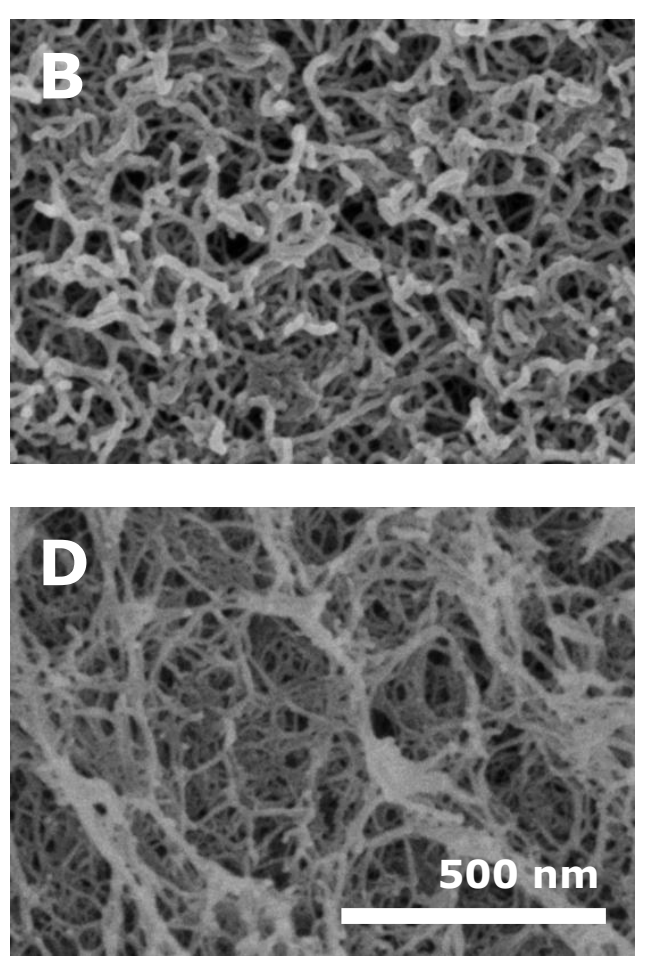